\title{
Distinct cleavage products of nuclear proteins in apoptosis and necrosis revealed by autoantibody probes
}

\author{
Carlos A. Casiano ${ }^{1,2}$, Robert L. Ochs ${ }^{1}$ and Eng M. Tan ${ }^{1}$ \\ ${ }^{1}$ WM Keck Autoimmune Disease Center, Department of Molecular and \\ Experimental Medicine, The Scripps Research Institute, La Jolla, California \\ 92037, USA \\ 2 corresponding author:W.M. Keck Autoimmune Disease Center, Department of \\ Molecular and Experimental Medicine SBR6, The Scripps Research Institute, \\ La Jolla, California 92037, USA. tel: 619-784-2364; \\ fax: 619-784-2131; e-mail: ccasiano@scripps.edu
}

Received 8.5.97; revised 11.8.97; accepted 22.9.97

Edited by D.R. Green

\begin{abstract}
A central mechanism in apoptosis is the activation of proteases of the caspase (cysteine aspartases) family. Protease activation has also been implicated in necrosis, but its role in this cell death process and the identity of the proteases involved and their substrates, are unknown. Using human autoantibodies to well characterized cellular proteins as detecting probes in immunoblotting, we observed that a defined and somewhat similar set of nuclear proteins, including poly (ADP-ribose) polymerase (PARP) and DNA topoisomerase I (Topo I), were selectively cleaved during both apoptosis and necrosis of cultured cells induced by various stimuli. The resulting cleavage products were distinctively different in the two cell death pathways. In contrast to apoptosis, the cleavages of PARP and Topo I during necrosis were not blocked by the caspase inhibitor benzyloxycarbonylVal-Ala-Asp-fluoromethyl ketone (zVAD-fmk). These findings suggest that different proteases act in apoptosis and necrosis, and that although both cell death processes result in selective cleavage of almost identical cellular proteins, they can be distinguished immunochemically on the basis of their cleavage products.
\end{abstract}

Keywords: autoantibodies; apoptosis; necrosis; nuclear proteins; proteases

Abbreviations: caspase, cysteine aspartase; DAPI, 4',6diamidino-2-phenylindole; $\mathrm{HgCl}_{2}$, mercuric chloride; $\mathrm{H}_{2} \mathrm{O}_{2}$, hydrogen peroxide; ICE, interleukin- $1 \beta$-converting enzyme; $\mathrm{mAb}$, monoclonal antibody; NP-40, Nonidet P-40; $\mathrm{OsO}_{4}$, osmium tetroxide; PARP, poly (ADP-ribose) polymerase; PBS, phosphate buffered saline; PCNA, proliferating cell nuclear antigen; SLE, systemic lupus erythematosus; Topo I, DNA topoisomerase I; SDS-PAGE, sodium dodecyl sulfate polyacrylamide gel electrophoresis; UBF, upstream binding factor of human RNA polymerase I; U1-70 kD, $70 \mathrm{kD}$ protein of the U1-small nuclear ribonucleoprotein particle; zVAD-fmk, benzyloxycarbonyl-Val-Ala-Asp-fluoromethyl ketone

\section{Introduction}

Apoptosis and necrosis are two morphologically distinct pathophysiological pathways of cell death (Wyllie et al, 1980; Buja et al, 1993; Majno and Joris, 1995). Apoptosis is genetically controlled and is defined by cytoplasmic and nuclear shrinkage, chromatin margination and fragmentation, and breakdown of the cell into multiple spherical bodies that retain membrane integrity. Necrosis is characterized by cytoplasmic swelling, nuclear pyknosis, and progressive loss of cytoplasmic membrane integrity (Wyllie et al, 1980; Buja et al, 1993; Majno and Joris, 1995). The latter feature leads to cellular fragmentation and release of lysosomal and granule contents into the surrounding extracellular space, with subsequent inflammation. These two cell death processes often occur simultaneously in a wide variety of pathological conditions as well as in cultured cells exposed to physiologic activators, physical trauma, or environmental toxins and chemicals (Wyllie et al, 1980; Arends and Wyllie, 1991; Buja et al, 1993; Majno and Joris, 1995; Thompson, 1995; Columbano, 1995; Rosser and Gores, 1995; Watson, 1995). The same type of insult can induce either apoptosis or necrosis but whether one mode of cell death is preferred over the other usually depends on the severity of the insult and the cell type (Lennon et al, 1991; Escargueil-Blanc et al, 1994; Bonfoco et al, 1995; Shimizu et al, 1996a). Necrosis can also occur as a secondary event following apoptosis (Majno and Joris, 1995; Tidbal et al, 1995). There is increasing evidence that some early biochemical events may be common to both cell death processes, while downstream mediators may be required to direct cells towards the execution of apoptosis or necrosis (Ankarkrona et al, 1995; Shimizu et al, 1996b; Leist et al, 1997; Leist and Nicotera, 1997).

Dissecting and discriminating the molecular mechanisms underlying apoptosis and necrosis is important for defining how cell death is regulated, understanding the role of cell death in pathology, designing approaches that could facilitate the modulation of cell death for therapeutic purposes, and establishing criteria for distinguishing unambiguously between these modes of cell death, an often difficult task, particularly in the context of pathological processes in vivo (Farber, 1994; Majno and Joris, 1995; Columbano, 1995). A wealth of recent evidence demonstrates that activation of a protease cascade involving members of the caspase family, formerly known as the ICE/ CED-3 protease family (Alnemri et al, 1996), is a central mechanism in the execution of apoptosis (Nicholson, 1996). The identification of this protease family was facilitated in part by the observation that a variety of nuclear proteins, in particular PARP, were degraded in cells undergoing apoptosis (Kaufmann, 1989; Kaufmann et al, 1993). Many of the substrates found to be cleaved during apoptosis are protein autoantigens targeted by antinuclear autoantibodies present in the sera of patients with systemic autoimmune 
diseases such as systemic lupus erythematosus (SLE), progressive systemic sclerosis (scleroderma), and Sjögren's syndrome (Casciola-Rosen et al, 1995; Casiano et al, 1996). This observation has made antinuclear autoantibodies useful probes for defining proteolytic events associated with cell death (Casiano and Tan, 1996).

There is evidence that protease activation also appears to be important in the execution of cell necrosis (EscargueilBlanc et al, 1994; Shimizu et al, 1996b; Aguilar et al, 1996), but the exact role of proteolysis in this mode of cell death and the identity of the proteases involved, and their substrates, are presently unknown. Using a panel of highly specific human autoantibodies to 18 well characterized intracellular protein autoantigens as detecting probes in immunoblotting, we show here that a defined and somewhat similar set of nuclear proteins, which includes PARP and Topo I, were selectively cleaved during both apoptosis and necrosis induced by a variety of stimuli. The resulting cleavage fragments were distinctively different in the two modes of cell death. Our findings indicate that necrosis, like apoptosis, is accompanied, at least during early stages, by specific cleavage of key nuclear substrates and not by a generalized degradation of intracellular material. Moreover, the results suggest that different proteases may underlie the execution of apoptosis and necrosis, and that these modes of cell death may be distinguished immunochemically on the basis of the cleavage products of certain nuclear proteins, in particular PARP and Topo I.

\section{Results}

\section{Induction of apoptosis and necrosis in Jurkat cells}

Figure 1a depicts time courses showing the percentages of Jurkat cells displaying apoptotic morphology and retaining cytoplasmic membrane integrity after treatment with either antiCD95 (Fas/APO-1) monoclonal antibody (mAb) $\mathrm{CH}-11,10 \%$ ethanol, $0.1 \%$ hydrogen peroxide $\left(\mathrm{H}_{2} \mathrm{O}_{2}\right) 40 \mu \mathrm{M}$ mercuric chloride $\left(\mathrm{HgCl}_{2}\right)$ or heat $\left(55^{\circ} \mathrm{C}\right)$. Cells incubated with antiCD95 mAb maintained membrane integrity, as inferred by their ability to exclude trypan blue (Figure 1a) and their nuclei displayed the characteristic apoptotic morphology (Figure 1b). Treatment with ethanol, $\mathrm{H}_{2} \mathrm{O}_{2}, \mathrm{HgCl}_{2}$, or heat produced a rapid decline in the number of cells maintaining membrane integrity, with no increase in the number of apoptotic cells relative to the untreated control cultures (Figure 1a), findings consistent with previous reports showing induction of cell necrosis under these conditions (Lennon et al, 1991; Shenker et al, 1993; Houge et
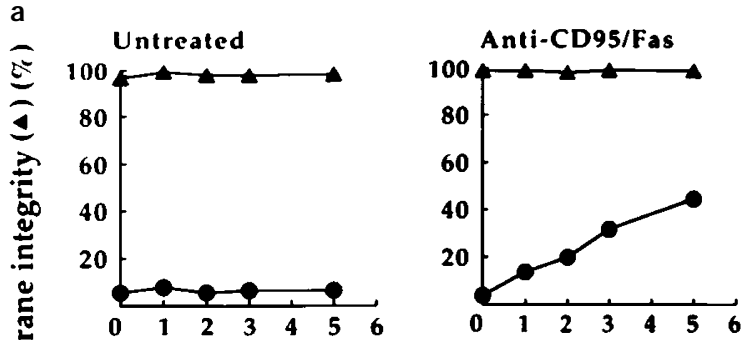

b
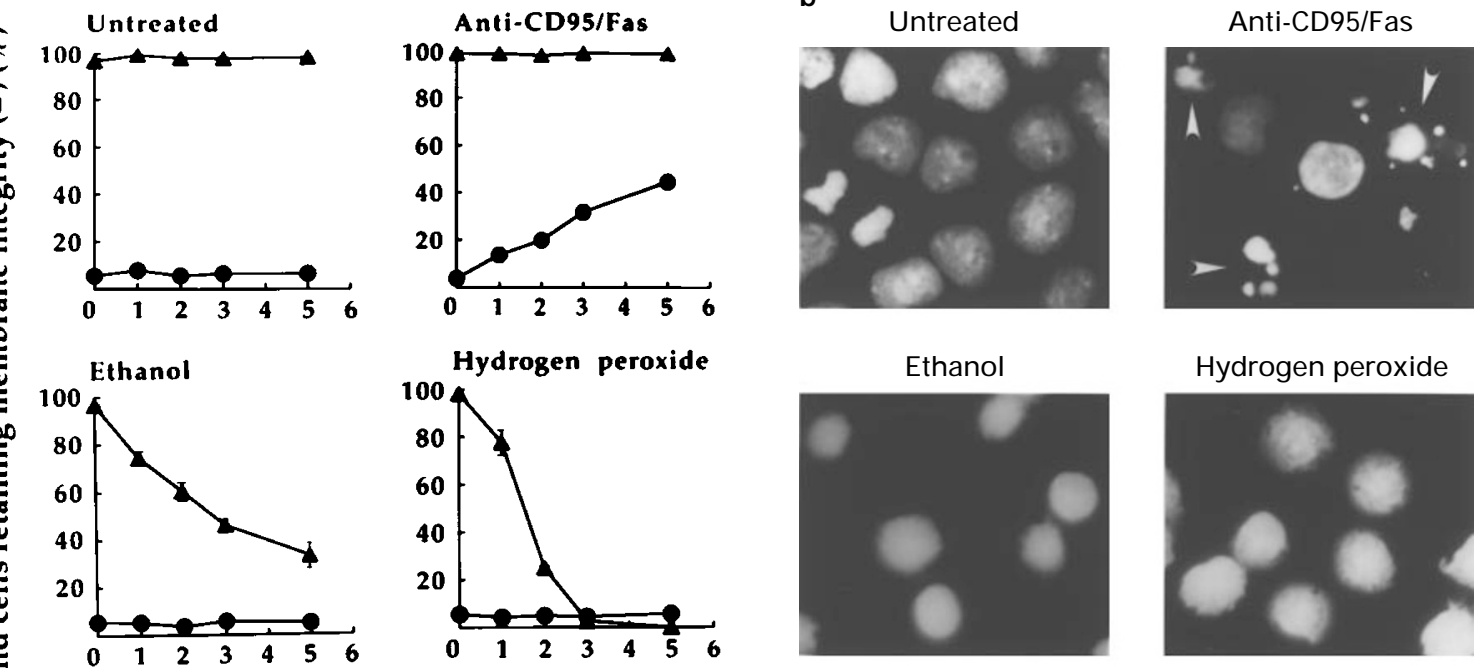

Hydrogen peroxide
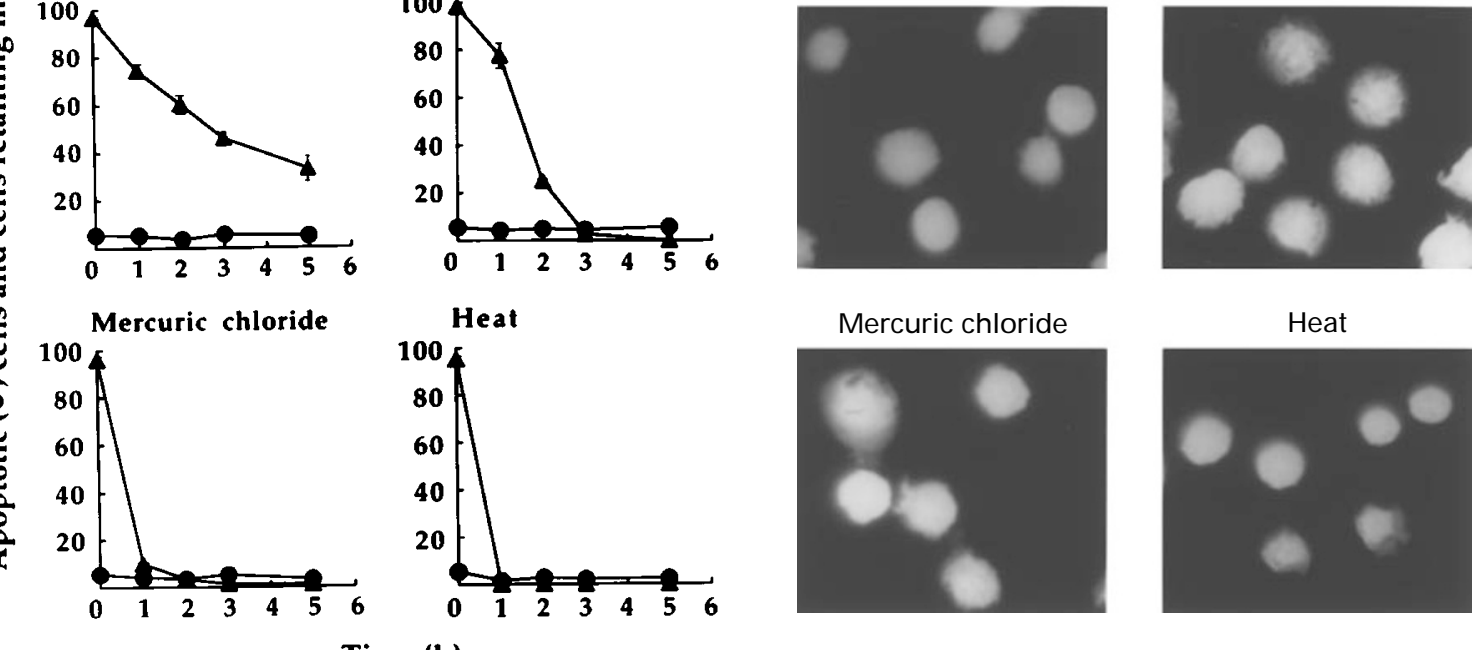

Time (h)

Figure 1 Induction of apoptosis and necrosis in Jurkat cells. (a) Progression of apoptosis and necrosis. Circles represent percentage of apoptotic cells whereas triangles represent percentage of cells retaining membrane integrity. Apoptosis was induced by exposure to anti-CD95/Fas mAb. Necrosis was induced with either $40 \mu \mathrm{M} \mathrm{HgCl}_{2}, 10 \%$ ethanol, $0.1 \%$ hydrogen peroxide, or heat $\left(55^{\circ} \mathrm{C}\right)$. Quantitation of apoptotic and necrotic cells was performed as described in Materials and Methods. A minimum of 200 cells from different fields were evaluated in four independent experiments. (b) DAPI-staining of nuclei from untreated, apoptotic, and necrotic Jurkat cells. Arrowheads point to apoptotic cells showing chromatin margination and multiple apoptotic bodies containing DAPI-positive staining material 
al, 1995). Treatment with $\mathrm{HgCl}_{2}$ and heat produced the most dramatic effects in cell viability (Figure 1a). Nuclei from cells incubated under necrosis-inducing conditions lacked the characteristic apoptotic morphology (Figure 1b).

A more definitive morphological distinction between apoptosis and necrosis in Jurkat cells was obtained by electron microscopy (Figure 2). Untreated cells (Figure 2A) were characterized by a single large nucleus containing a prominent nucleolus. Treatment with anti-CD95 mAb (Figure 2B) led to nuclear shrinkage with the characteristic apoptosis-associated chromatin condensation and margination, and a round compact nucleolus. The cytoplasm appeared relatively normal and intact. The morphology of cells treated with ethanol, $\mathrm{H}_{2} \mathrm{O}_{2}, \mathrm{HgCl}_{2}$, or heat was different. Ethanol treatment (Figure $2 \mathrm{C}$ ) resulted in a shrunken nucleus with an identifiable nucleolus and condensed chromatin. Both the nucleus and the cytoplasm were extensively damaged by this treatment. $\mathrm{H}_{2} \mathrm{O}_{2}$ treatment (Figure 2D) left the nucleus and the nucleolus relatively intact, with a small amount of condensed chromatin. The cytoplasm, however, was heavily damaged, with no identifiable organelles. Treatment with $\mathrm{HgCl}_{2}$ (Figure 2E) resulted in swollen and broken cells with no intact nuclei or cytoplasm. Condensed chromatin was absent but remnants of nucleoli were still identifiable. Heat treatment (Figure $2 \mathrm{~F}$ ) resulted in cells with broken nuclei and cytoplasm and condensed nucleoli.

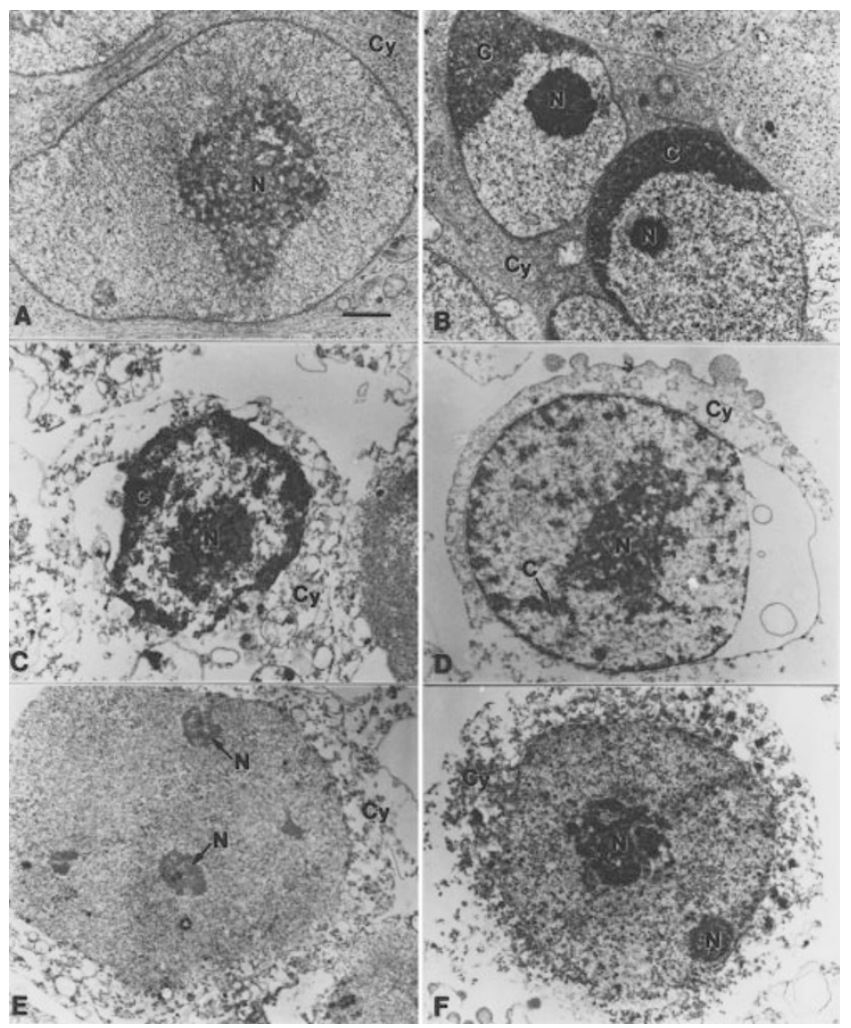

Figure 2 Electron microscopy of Jurkat cells treated for $4 \mathrm{~h}$ with various stimuli to induce cell death by apoptosis or necrosis. (A) Untreated control, (B) anti-CD95/Fas mAb, (C) $10 \%$ ethanol, (D) $0.1 \%$ hydrogen peroxide, (E) $40 \mu \mathrm{M}$ $\mathrm{HgCl}_{2}$, and $(\mathbf{F})$ heat $\left(55^{\circ} \mathrm{C}\right)$. N, nucleolus; $\mathrm{C}$, chromatin, Cy, cytoplasm. Bar represents $1 \mu \mathrm{m}$

\section{Apoptosis and necrosis of Jurkat cells are associated with selective but distinctively different patterns of nuclear protein cleavage}

To determine whether necrosis is associated with cleavage of specific cellular proteins, we examined 18 well characterized protein autoantigens (nuclear and cytoplasmic) by immunoblotting of Jurkat lysates prepared from control (untreated), anti-CD95-treated, and $\mathrm{HgCl}_{2}$-treated cells. Human autoimmune sera containing highly specific autoantibodies to these proteins were used as detecting reagents. Three proteins, PARP, Topo I, and the human RNA polymerase I upstream binding factor (UBF), were cleaved during both CD95-mediated apoptosis and $\mathrm{HgCl}_{2}$ induced necrosis, as judged by the appearance of lower molecular weight bands in blots concomitant with a proportional reduction in the amount of the intact protein (Figure 3). Interestingly, the resulting proteolytic fragments were in general distinctively different between apoptosis and necrosis (data summarized in Table 1). The cleavage of Topo I during apoptosis generated the signature $70 \mathrm{kD}$ apoptotic fragment described previously (Casiano et al, 1996) (Figure 3). Although this fragment also appeared during necrosis, the predominant cleavage product of Topo I in this mode of cell death was a fragment of approximately $45 \mathrm{kD}$. Other lower molecular weight cleavage products were also observed. PARP cleavage during apoptosis generated the signature $85 \mathrm{kD}$ fragment (Kaufmann et al, 1993; Casciola-Rosen et al, 1995; Casiano et al, 1996) (Figure 3) but in $\mathrm{HgCl}_{2}$-induced necrosis several bands were observed, with a predominant cleavage product of approximately $50 \mathrm{kD}$. Traces of the apoptotic $85 \mathrm{kD}$ fragment were observed in some necrotic lysates. The $70 \mathrm{kD}$ protein of the U1-small nuclear ribonucleoprotein particle (U1-70 kD) was cleaved during apoptosis into the signature $40 \mathrm{kD}$ fragment (Casciola-Rosen et al, 1995; Casiano et al, 1996) (Figure 3). However, neither the native protein nor any cleavage fragments were detected in lysates from $\mathrm{HgCl}_{2-}$ treated cells. In addition, an unidentified $33 \mathrm{kD}$ protein that is also recognized by this particular autoimmune serum was not detected in these lysates. Several possibilities may explain this lack of immunoreactivity, including complete protein degradation, destruction of the autoreactive epitopes by limited proteolysis, or solubilization and release of the proteins during necrosis. Consistent with our previous report (Casiano et al, 1996), UBF was cleaved during apoptosis into several fragments ranging from $24 \mathrm{kD}$ to $55 \mathrm{kD}$ (Figure 3 ). During necrosis, however, this protein was cleaved into fragments ranging from $45 \mathrm{kD}$ to $75 \mathrm{kD}$, without detectable 32 and $24 \mathrm{kD}$ fragments (Figure 3). Lamin B (68 kD) was also affected differently in apoptosis and necrosis. During apoptosis the protein was cleaved into the signature $45 \mathrm{kD}$ fragment (Casiano et al, 1996) (Figure 3). Although a reduction in the intensity of the intact lamin $B$ protein in necrotic lysates was observed in some blots, we were not able to detect a defined cleavage fragment with the autoimmune serum used in these experiments. This would be consistent with the recent observation that lamin B does not appear to be cleaved under conditions of ATP depletion leading to necrosis (Leist et al, 1997). 


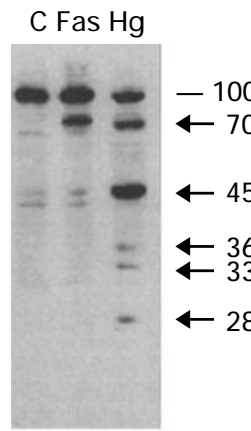

Topo I

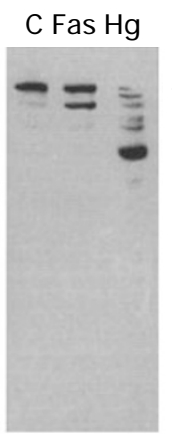

PARP

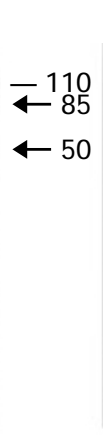

C Fas Hg

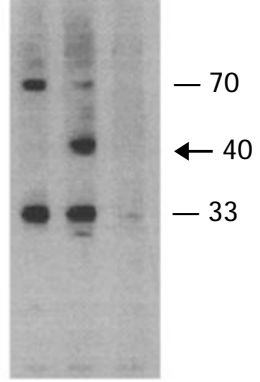

U1-70 kD

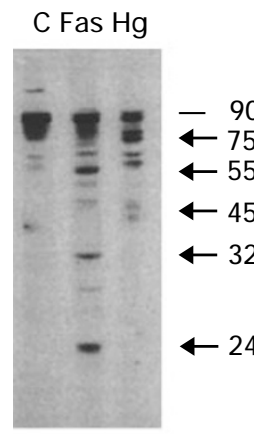

UBF
C Fas Hg

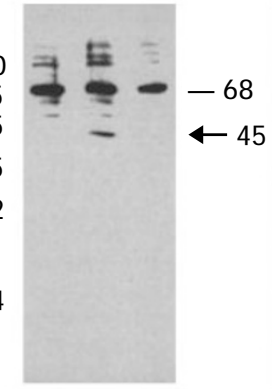

Lamin B

C Fas Hg

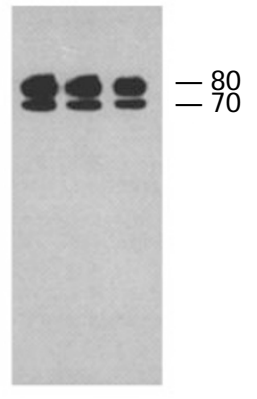

$\mathrm{Ku}$

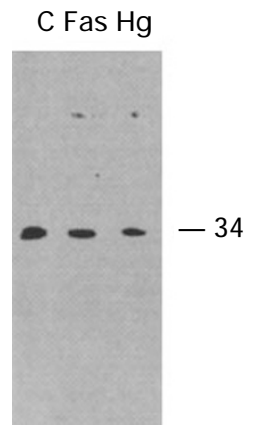

PCNA

C Fas $\mathrm{Hg}$

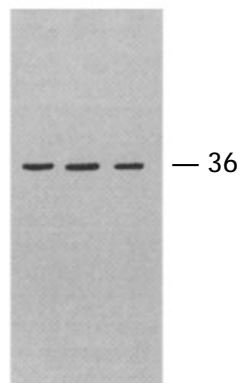

Fibrillarin

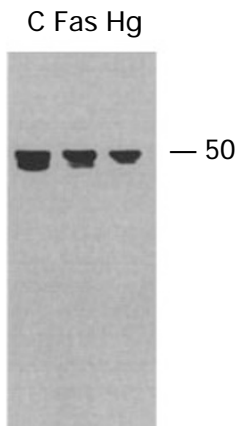

J 0-1

Figure 3 Cleavage of a subset of protein autoantigens during CD95/Fasmediated apoptosis and $\mathrm{HgCl}_{2}$-mediated necrosis in Jurkat cells. Cells were exposed to either anti-CD95/Fas $\mathrm{mAb}(7 \mathrm{~h})$ or $40 \mu \mathrm{M} \mathrm{HgCl}_{2}(5 \mathrm{~h})$ prior to harvesting for lysate preparation. Representative blots of lysates from control (C), apoptotic (Fas), and necrotic $(\mathrm{Hg})$ cells probed with various human autoimmune sera are shown. Intact proteins are indicated by lines, whereas proteolytic fragments are indicated by arrows. Numbers to the right of each blot represent relative molecular weight in $\mathrm{kD}$

Protein cleavage during $\mathrm{HgCl}_{2}$-induced necrosis did not appear to be indiscriminate since no evidence of cleavage was detected with our autoantibodies in many other intracellular proteins. These included the DNA binding protein Ku, PCNA, nucleolar protein fibrillarin, histidyl-tRNA synthetase (known as the Jo-1 autoantigen) (Figure 3), and the Sm autoantigen (involved in mRNA splicing), the coiledbody associated protein p80 coilin, the nuclear protein SSA/ $\mathrm{Ro}$, the nucleolar proteins $\mathrm{B} 23, \mathrm{PM}-\mathrm{Scl}$ and To, and the ribosomal proteins $\mathrm{P} 1, \mathrm{P} 2$ and $\mathrm{P0}$ (data not shown).

Table 1 Nuclear protein autoantigens cleaved during apoptosis and necrosis in Jurkat cells

\begin{tabular}{lccc}
\hline Protein & MW & $\begin{array}{c}\text { Major cleavage } \\
\text { fragments } \\
\text { in apoptosis }\end{array}$ & $\begin{array}{c}\text { Major cleavage } \\
\text { fragments } \\
\text { in necrosis }\end{array}$ \\
\hline Lamin B & $68 \mathrm{kD}$ & $45 \mathrm{kD}$ & Not detected \\
PARP & $110 \mathrm{kD}$ & $85 \mathrm{kD}$ & $50 \mathrm{kD}$ \\
Topo I & $100 \mathrm{kD}$ & $70 \mathrm{kD}$ & $70,45 \mathrm{kD}$ \\
UBF & $90 \mathrm{kD}$ & multiple & multiple \\
& & $(24,32,55 \mathrm{kD})$ & $(45-75 \mathrm{kD})$ \\
U1-70 kD & $70 \mathrm{kD}$ & $40 \mathrm{kD}$ & completely \\
& & & degraded (?) \\
\hline
\end{tabular}

Cleavage fragments were detected by immunoblotting of apoptotic and necrotic cell lysates using human autoantibodies as detecting probes. Protein autoantigens that did not appear cleaved during either apoptosis or necrosis included the nuclear proteins SSA/Ro, p80 coilin, Ku, PCNA, and Sm; nucleolar proteins B23, fibrillarin, PM-Scl, and To; histidyl RNA synthetase (Jo-1); and ribosomal proteins $\mathrm{P} 0, \mathrm{P} 1$, and $\mathrm{P} 2$

\section{A common pattern of protein cleavage is associated with different types of necrotic cell death}

It was important to determine whether the protein cleavages observed during $\mathrm{HgCl}_{2}$-induced cell death could be also reproduced in Jurkat cells induced to die by necrosis with $10 \%$ ethanol, $0.1 \% \mathrm{H}_{2} \mathrm{O}_{2}$, and $55^{\circ} \mathrm{C}$ heat. Figure $4 \mathrm{a}$ shows that under all the necrosis-inducing conditions, Topo I was predominantly cleaved into 70 and $45 \mathrm{kD}$ fragments, whereas PARP was cleaved predominantly into a $50 \mathrm{kD}$ fragment. An additional PARP fragment of approximately $62 \mathrm{kD}$ was observed in ethanol-treated cells. The degradation patterns of UBF and U1-70 kD were also similar, respectively, under the four necrosis-inducing conditions (data not shown). To demonstrate that these necrosis-associated cleavages were not limited to Jurkat cells, necrosis was induced in HL-60 cells with $40 \mu \mathrm{M} \mathrm{HgCl}_{2}$. Immunoblotting analysis of apoptotic (induced by etoposide/VP-16) and necrotic HL-60 cells revealed patterns of protein cleavage identical to those observed in Jurkat cells (Figure $4 \mathrm{~b}$ and data not shown). Similar results were obtained in $\mathrm{J} 774$ murine macrophages induced to undergo necrosis with $40 \mu \mathrm{M} \mathrm{HgCl}_{2}$ (data not shown). The observed cleavage of PARP into a $50 \mathrm{kD}$ fragment during necrosis is consistent with the observation that necrosis in HL-60 cells induced by cytochalasin B is accompanied by degradation of PARP into a $50 \mathrm{kD}$ polypeptide (Shah et al, 1996). These results suggest the activity of common proteases in different forms of necrotic cell death.

\section{zVAD-fmk blocks cleavages of PARP and Topo I during apoptosis but not during necrosis}

We determined whether zVAD-fmk, a cell permeable tripeptide inhibitor of caspases and apoptosis (Sarin et al, 1996), was capable of blocking necrosis-associated proteolysis in Jurkat cells. Cells were incubated with $10 \mu \mathrm{M}$ of zVADfmk for $1 \mathrm{~h}$ prior to induction of apoptosis with anti-CD95 mAb, or necrosis with $\mathrm{HgCl}_{2}$. zVAD-fmk blocked the morphological features of apoptosis (data not shown) as well as the cleavage of PARP and Topo I in anti-CD95 treated cells (Figure 5) but 
did not retard the progression of $\mathrm{HgCl}_{2}$-induced necrosis (Table 2) nor the cleavage of PARP and Topo I during this mode of cell death (Figure 5).

\section{Rapid cell lysis induced by non-ionic detergent results in autoantigen cleavage patterns relatively different from those generated during necrosis}

To test the possibility that the autoantigen cleavages observed in necrotic cells were simply due to massive release of compartmentalized proteases during cell lysis, untreated cells were quickly lysed in buffer containing $1 \%$

a
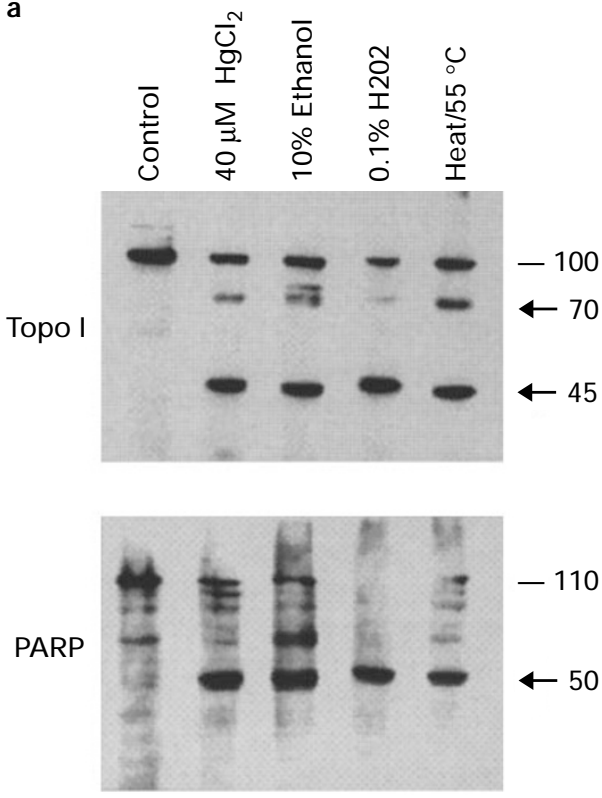

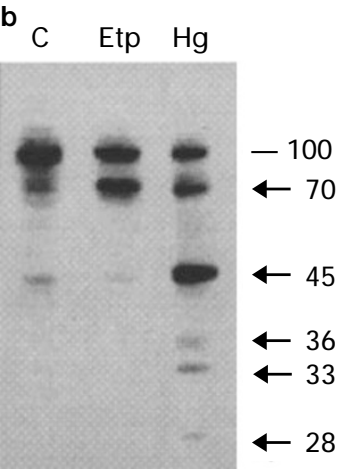

Topo I
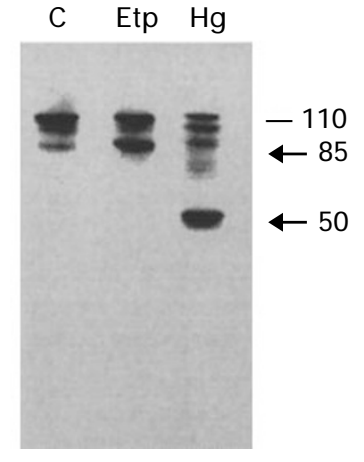

PARP
Figure 4 Immunoblots showing cleavage of Topo I and PARP in different types of necrotic cell death. (a) Cleavage of Topo I and PARP in Jurkat cells incubated for $5 \mathrm{~h}$ under various necrosis-inducing conditions. (b) Cleavage of Topo I and PARP during etoposide-mediated apoptosis and $\mathrm{HgCl}_{2}$-induced necrosis in HL-60 cells. Cells were exposed to either $150 \mu \mathrm{M}$ etoposide or $40 \mu \mathrm{M} \mathrm{HgCl}_{2}$ for $6 \mathrm{~h}$. Representative blots of lysates from control (C), apoptotic (Etp), and necrotic $(\mathrm{Hg})$ cells probed with human autoimmune sera are shown. Intact proteins are indicated by lines, whereas proteolytic fragments are indicated by arrows. Numbers to the right of each blot represent relative molecular weight in $\mathrm{kD}$
Nonidet P-40 (NP-40), $50 \mathrm{mM} \mathrm{NaCl}$, and $10 \mathrm{mM}$ HEPES, $\mathrm{pH}$ 7.0 (Casciola-Rosen et al, 1994). Lysates were incubated at $37^{\circ} \mathrm{C}$ for up to $5 \mathrm{~h}$. Figure 6 shows that Topo I was cleaved differently in necrotic cells and in the NP-40 lysates since the $45 \mathrm{kD}$ and smaller fragments generated during necrosis were not present in these lysates. Instead, proteolytic products ranging from $70-80 \mathrm{kD}$ were present in the NP-40 lysates. These lysates also yielded PARP fragments of approximately 85, 62, and $50 \mathrm{kD}$ (Figure 6), suggesting that proteases responsible for PARP cleavage during both apoptosis and necrosis had accessibility to this protein in these lysates. The $62 \mathrm{kD}$ PARP fragment that appeared in the NP-40 lysates
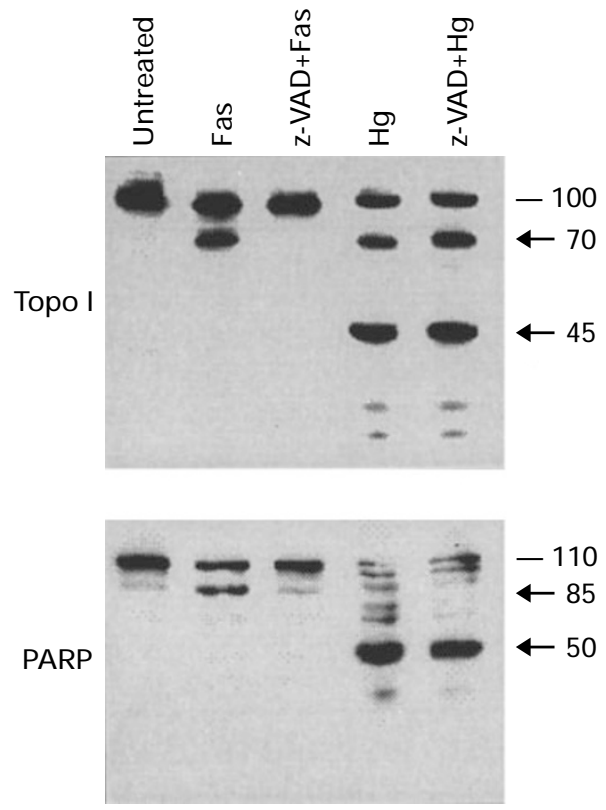

Figure 5 zVAD-fmk inhibits the proteolytic cleavages of Topo I and PARP during CD95/Fas-mediated apoptosis of Jurkat cells but has no effects on these cleavages during $\mathrm{HgCl}_{2}$-induced necrosis. zVAD-fmk $(10 \mu \mathrm{M})$ was added to cell cultures $1 \mathrm{~h}$ prior to addition of either anti-CD95/Fas mAb or $\mathrm{HgCl}_{2}(40 \mu \mathrm{M})$. Cells were incubated for $5 \mathrm{~h}$ prior to harvesting for lysate preparation. Intact proteins are indicated by lines, whereas proteolytic fragments are indicated by arrows. Numbers to the right of each blot represent relative molecular weight in $\mathrm{kD}$

Table 2 Assessment of loss of membrane integrity in Jurkat cells induced to die by apoptosis and necrosis after pre-treatment with zVAD-fmk

\begin{tabular}{lc}
\hline Treatment & $\begin{array}{c}\text { Cell retaining membrane } \\
\text { integrity (\%) }\end{array}$ \\
\hline Control & $92.1 \pm 5.3$ \\
Anti-CD95/Fas mAb & $90.3 \pm 5.1$ \\
zVAD-fmk+anti-CD95/Fas mAb & $89.3 \pm 6.7$ \\
$\mathrm{HgCl}_{2}$ & 0 \\
zVAD-fmk+HgCl & 0 \\
\hline
\end{tabular}

Jurkat cells were pre-treated with zVAD-fmk $(10 \mu \mathrm{M})$ for $1 \mathrm{~h}$ prior to induction of apoptosis with anti-CD95/Fas $\mathrm{mAB}$ or necrosis with $\mathrm{HgCl}_{2}(40 \mu \mathrm{M})$. After incubation for $5 \mathrm{~h}, 100 \mu \mathrm{l}$ aliquots of the cell cultures were mixed with $10 \mu \mathrm{l}$ of a $0.4 \%$ trypan blue solution and the cells counted in a hemacytometer. At least 200 cells were counted in three separate experiments. Loss of membrane integrity was measured by the ability of cells to take up trypan blue and was considered as indicative of cell necrosis 

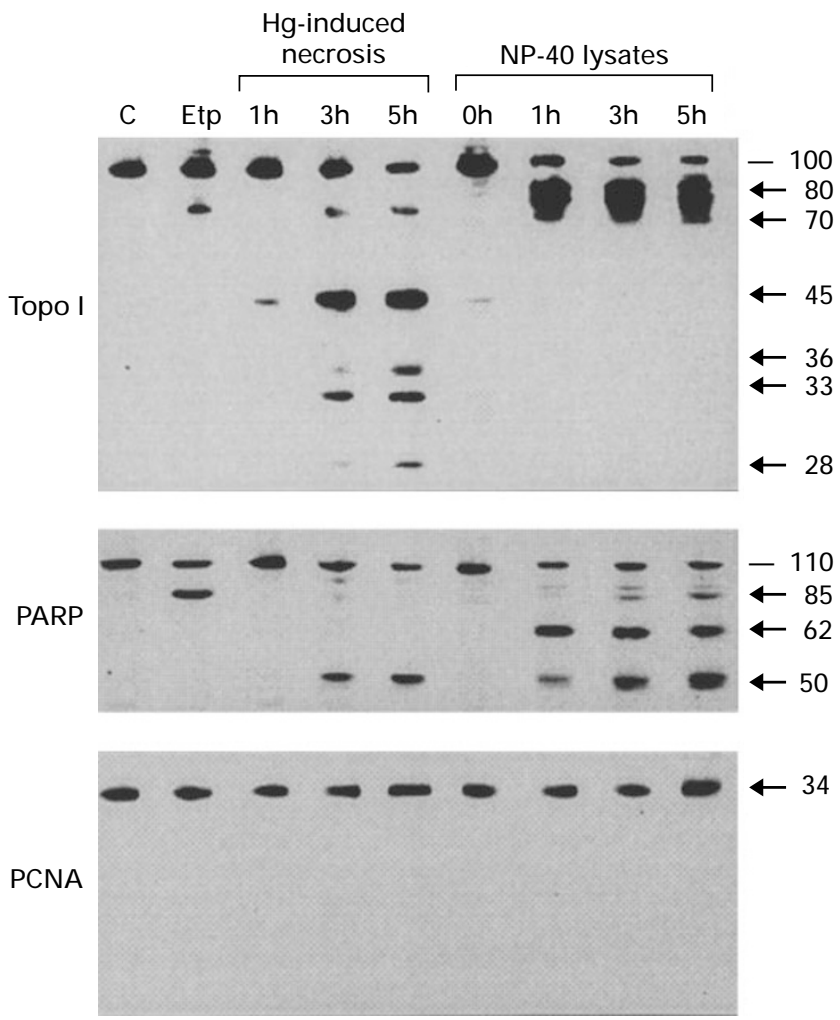

Figure 6 Proteolysis of Topo I and PARP during cell lysis induced by buffer containing NP-40. Jurkat cells were induced to die by apoptosis with $150 \mu \mathrm{M}$ etoposide (Etp), by necrosis with $40 \mu \mathrm{M} \mathrm{HgCl}$, or directly lysed in buffer containing $1 \% \mathrm{NP}-40,50 \mathrm{mM} \mathrm{NaCl}$, and $10 \mathrm{mM}$ HEPES, pH 7.0. Comparison of the autoantigen cleavage patterns in apoptotic, necrotic, and lysed cells reveals both common and different proteolytic products. Intact proteins are indicated by lines, whereas proteolytic fragments are indicated by arrows

was not observed in lysates from $\mathrm{HgCl}_{2}$-treated cells, but a fragment with similar size was observed in ethanol-induced necrosis (Figure 4a). UBF, which is degraded into several fragments during necrosis, was not cleaved in the NP-40 lysates, whereas $\mathrm{U} 1-70 \mathrm{kD}$, which is completely degraded in necrosis, also appeared completely degraded in the lysates (data not shown). Proteins that were not found cleaved during apoptosis or necrosis, such as PCNA, Ku, fibrillarin, and Jo-1 were not affected by proteases in the NP-40 lysates (Figure 6 and data not shown).

\section{Discussion}

Human antinuclear autoantibodies are valuable tools for defining proteolytic events associated with apoptotic cell death (Casciola-Rosen et al, 1995; Casiano et al, 1996; Casiano and Tan, 1996). The value of these reagents is enhanced by their reactivity with multiple epitopes within the target antigen (Tan, 1989), which facilitates the characterization of cleavage fragments that may escape detection by immunoblotting when linear sequence-targeting antibodies are used. In this study, we used antinuclear autoantibodies as probes for detecting proteolytic cleavage of certain substrates during apoptosis and necrosis. A major finding was that necrosis is associated with proteolysis of a limited number of nuclear autoantigens, which indicates that this mode of cell death may involve, at least during the early stages, a selective rather than generalized degradation of proteins. A caveat to this finding is that proteins that appear not cleaved during cell death might be partially degraded but the degradation products are not recognized by the autoantibodies. Although not exhaustive, 18 protein autoantigens were examined by immunoblotting and, with the possible exception of lamin B, only those proteins that were degraded during apoptosis were found degraded during necrosis. In the case of U1-70 kD, failure to identify residual intact protein during necrosis might indicate extensive degradation but at the same time inability to identify cleavage fragments introduces some uncertainty to this assumption. In general, the cleavage fragments produced during necrosis were different from those produced during apoptosis, suggesting that different proteases operate in the two cell death pathways. The only cleavage fragment that was clearly common to both modes of cell death was the $70 \mathrm{kD}$ polypeptide derived from Topo I, suggesting that the protease responsible for this cleavage during apoptosis might also be activated or released during necrosis. This would be consistent with recent studies showing that certain forms of necrosis can be retarded by specific inhibitors of caspases, leading to the proposal that apoptosis and necrosis may share some common mediators (Shimizu et al, 1996b). Alternatively, the $70 \mathrm{kD}$ fragments of Topo I that arise during apoptosis and necrosis may be unrelated and generated fortuitously in both cell death processes by different proteases.

The observation that neither necrosis nor the cleavages of Topo I and PARP during this mode of cell death were blocked by zVAD-fmk implies that the caspases specifically inhibited by this tripeptide may not be involved in the execution of necrosis. This would further support the interpretation that different proteases may operate in apoptosis and necrosis. Although caspases have been clearly implicated in the cleavage of specific cellular proteins during apoptosis (Nicholson, 1996; Porter et al, 1997), it remains to be determined whether necrosis occurs by a pathway that is either completely or partially independent of caspase activation. It is possible that acute cell damage leading to necrosis may result in the observed proteolytic events due simply to the release of compartmentalized proteases. Our data indicate that rapid cell lysis by itself may contribute to the generation of some but not all the cleavages observed during necrosis. It cannot be ruled out the possibility that some lysosomal or cytosolic proteases which might be responsible for the necrosisassociated cleavages were inactive in our NP-40 lysates.

The present findings clearly suggest that a defined and somewhat similar set of key cellular proteins is targeted for proteolysis, albeit apparently by different proteases, regardless of how cell death is executed. The biological significance of this observation is unclear. One possibility is that these proteins may possess protease sensitive sites or motifs that are specifically targeted by proteases acting during apoptosis or necrosis. This would imply that by coincidence a similar or almost identical set of intracellular proteins possess both apoptosis-related and necrosis- 
related cleavage sites. Perhaps another explanation could be that these cellular proteins are the early or key proteins targeted in either apoptotic or necrotic cell death pathways. The manner in which these proteins are cleaved may facilitate the phenotypic changes that characterize these modes of cell death. There is evidence that proteolysis of certain substrates may facilitate some of the morphological events associated with apoptosis (Rao et al, 1996; Liu et al, 1997; Porter et al, 1997), but similar evidence for necrosis is not yet available.

The morphological distinction between apoptosis and necrosis is relatively well defined. However, discriminating between these modes of cell death using non-morphological criteria has been more difficult due to the scarcity of biochemical or immunological markers of these cell death processes. The observed differences in the cleavage patterns of PARP and Topo I during apoptosis and necrosis should be useful for defining additional biochemical and immunological criteria which can be used to clearly discriminate between these modes of cell death. We propose that the unique cleavage products of PARP (50 kD) and Topo I (45 kD) associated with several forms of necrosis could be considered as markers of this cell death process.

Finally, analysis of protein autoantigen cleavage during apoptosis and necrosis might also provide insights into the possible role of cell death in the generation of potentially immunostimulatory forms of cellular antigens in systemic autoimmune diseases. It has been speculated that apoptotic cleavage of certain autoantigens might be a mechanism by which cryptic epitopes are revealed leading to an immunogenic response (Casciola-Rosen et al, 1995). In previous studies (Casciola-Rosen et al, 1995; Casiano et al, 1996) and in this study, it can be appreciated that this mechanism, if operational, would apply only to a relatively small subset of known autoantigens since the majority of autoantigens that are recognized by autoantibodies in systemic autoimmunity do not appear to be cleaved during cell death. If such an immunostimulatory mechanism exists, then both apoptosis and necrosis would need to be considered as possible processes stimulating putative autoimmune responses, since autoantigen cleavage in the two modes of cell death appears to involve a similar set of proteins.

\section{Materials and Methods}

\section{Materials}

Jurkat (human T cell leukemia) and HL60 cells (human promyelocytic leukemia) were obtained from American Type Culture Collection (Rockville, MD) and cultured under standard conditions in RPMI 1640 medium. Human autoantibodies were from the serum bank of the W.M. Keck Autoimmune Disease Center of The Scripps Research Institute. Anti-CD95 (Fas/APO-1) mAb CH-11 was from Medical and Biological Laboratories (Watertown, MA). $\mathrm{HgCl}_{2}$ was from Baxter Chemical Co. (Philipsburg, $\mathrm{NJ}$ ), $\mathrm{H}_{2} \mathrm{O}_{2}$ from Fisher (Pittsburg, $\mathrm{PA}$ ), and ethanol from Quantum Chemical Corporation (Tuscola, IL). Etoposide was from Sigma Chemical Co. (St. Louis, MO) and zVAD-fmk from Kamiya Biomedical Company (Tukwila, WA).

\section{Induction of cell death}

Apoptosis was induced with either anti-CD95 mAb (100-200 ng/ml, Jurkat cells only) or by exposure of cell cultures $\left(10^{6} \mathrm{cell} / \mathrm{s} / \mathrm{ml}\right)$ to the antitumor drug etoposide/VP-16 $(150 \mu \mathrm{M})$, for up to $7 \mathrm{~h}$. Necrosis was induced by exposure of cell cultures to conditions that have been shown in previous studies to induce necrotic cell death in a variety of cell lines (Lennon et al, 1991; Shenker et al, 1993; Houge et al, 1995). These conditions consisted of treatment with either $40 \mu \mathrm{M} \mathrm{HgCl}_{2}, 10 \%$ ethanol, $0.1 \% \mathrm{H}_{2} \mathrm{O}_{2}$, or $55^{\circ} \mathrm{C}$ heat, for up to $5 \mathrm{~h}$. Spontaneous cell death prior to the experiments was minimized by diluting the cell cultures in fresh medium every $2-3$ days to maintain exponential growth.

\section{Electron microscopy}

Jurkat cells were treated for $4 \mathrm{~h}$ with anti-CD95 mAb to induce apoptosis and with either $40 \mu \mathrm{M} \mathrm{HgCl}_{2}, 10 \%$ ethanol, $0.1 \% \mathrm{H}_{2} \mathrm{O}_{2}$, or heat $\left(55^{\circ} \mathrm{C}\right)$ to induce necrosis. Cells were pelleted and fixed for $1 \mathrm{~h}$ at room temperature in $2.5 \%$ glutaraldehyde buffered with $0.1 \mathrm{M}$ cacodylate ( $\mathrm{pH} 7.2)$, rinsed in cacodylate buffer, postfixed $1 \mathrm{~h}$ in $2 \%$ osmium tetroxide $\left(\mathrm{OsO}_{4}\right)$ buffered with cacodylate, dehydrated in a graded ethanol series, and embedded in Polybed 812 (Polysciences). Thin sections were stained with uranyl acetate and lead citrate.

\section{Identification and quantitation of apoptotic and necrotic cells}

The criteria for the identification of apoptotic cells included cell shrinkage, chromatin margination and fragmentation, and formation of apoptotic bodies, as visualized by electron microscopy as well as fluorescence microscopy of nuclei stained with $0.1 \mu \mathrm{g} / \mathrm{ml}$ of $4^{\prime}, 6-$ diamidino-2-phenylindole (DAPI). Cells with morphological characteristics of apoptosis excluded trypan blue. The criteria for the identification of necrotic cells included cytoplasmic swelling, nuclear pyknosis, absence of chromatin margination and fragmentation, absence of apoptotic body formation, and loss of cytoplasmic membrane integrity. Invariably, cells with morphological characteristics of necrosis were trypan blue positive, consistent with previous observations (Lennon et al, 1991). Quantitation of apoptotic and necrotic cells was performed essentially as described previously (Lennon et al, 1991). Briefly, $100 \mu$ l aliquots $\left(10^{5}\right.$ cells) were removed from cell cultures, centrifuged at $2000 \mathrm{~g}$ for $10 \mathrm{~min}$, and resuspended in $100 \mu \mathrm{l}$ of PBS containing $2 \%$ paraformaldehyde and DAPI. The cell suspension was then applied to a glass slide and DAPI-stained nuclei were visualized by fluorescence microscopy. Cells whose nuclei unambiguously displayed the apoptotic morphology were scored as apoptotic. For the quantitation of necrotic cells, an aliquot of the cell suspension was mixed with a trypan blue solution and the positivelystained cells were counted as necrotic. At least 200 cells were counted in each experiment.

\section{Electrophoresis and immunoblotting of cell lysates}

For lysate preparation, control, apoptotic, and necrotic cells were centrifuged at 3000 r.p.m. for 20 min, followed by two washes (11 000 r.p.m. for $10 \mathrm{~min}$ ) in PBS containing the CØMPLETE Protease Inhibitor Cocktail (Boehringer Mannheim, Germany). Cells were then resuspended at approximately $10^{7} \mathrm{cell} / \mathrm{s} / \mathrm{ml}$ in SDS-lysis buffer containing $62.5 \mathrm{mM}$ Tris- $\mathrm{HCl}, \mathrm{pH} 6.8,1 \%$ SDS, $10 \%$ glycerol, $1 \%$ mercaptoethanol, and the protease inhibitor cocktail. Prior to electrophoresis, lysates were boiled for $5 \mathrm{~min}$ to solubilize protein, passed through a 27-gauge needle to shear the DNA, and stored at 
$-70^{\circ} \mathrm{C}$ until required. For some experiments, control cells were lysed at a concentration of $10^{7}$ cells $/ \mathrm{ml}$ in buffer containing $1 \%$ NP-40, $50 \mathrm{mM} \mathrm{NaCl}$, and $10 \mathrm{mM}$ HEPES, pH 7.0. Cell lysis under these conditions occurred rapidly since visualization of cells by light microscopy minutes after addition of the lysis buffer revealed heavy cell damage with trypan blue uptake. After incubation at $37^{\circ} \mathrm{C}$, these NP-40 lysates were mixed with an equal volume of SDS-lysis buffer and processed for electrophoresis as indicated above. Total protein from approximately $10^{6}$ cells were added to individual lanes and separated by SDS-PAGE followed by transfer to nitrocellulose at $250 \mathrm{~mA}$ for $4-5 \mathrm{~h}$. Immunoblotting procedures were as described previously (Casiano et al, 1996). Detection of bound autoantibodies was achieved using a horseradish peroxidase-conjugated goat antihuman IgG secondary antibody (Zymed, South San Francisco, CA) at a 1:3000 dilution, in combination with the enhanced chemiluminescence method (ECL, Amersham Life Science, Cleveland, $\mathrm{OH}$ ).

\section{Acknowledgements}

We thank Drs K Michael Pollard (The Scripps Research Institute, La Jolla), Martin Blüthner (University of Heidelberg, Germany), Guy Salvesen (The Burnham Institute, La Jolla), Seamus J Martin (Maynooth College, Ireland) and Douglas R Green (La Jolla Institute for Allergy and Immunology) for valuable discussions and suggestions. This work was supported by grants from the National Institutes of Health. CAC was supported in part by a Postdoctoral Fellowship Award from the Arthritis Foundation. This is publication number 10638-MEM from The Scripps Research Institute.

\section{References}

Aguilar HI, Botla R, Arora A, Bronk SF and Gores GJ (1996) Induction of the mitochondrial permeability transition by protease activity in rats: a mechanism of hepatocyte necrosis. Gastroenterology 110: 558-566

Alnemri ES, Livingston DJ, Nicholson DW, Salvesen G, Thornberry NA, Wong W and Yuan J (1996) Human ICE/CED-3 protease nomenclature. Cell 87: 171

Ankarkrona M, Dypbukt JM, Bonfoco E, Zhivotovsky B, Orrenius S, Lipton SA and Nicotera P (1995) Glutamate-induced neuronal death: a succession of necrosis or apoptosis depending on mitochondrial function. Neuron 15: $961-973$

Arends MJ and Wyllie AH (1991) Apoptosis: mechanisms and role in pathology. Int. Rev. Exp. Pathol. 32: 223-254

Bonfoco E, Krainc D, Ankarcrona M, Nicotera P and Lipton SA (1995) Apoptosis and necrosis: two distinct events induced, respectively, by mild and intense insults with $\mathrm{N}$-methyl-D-aspartate or nitric oxide/superoxide in cortical cell cultures Proc. Natl. Acad. Sci. USA 92: 7162-7166

Buja LM, Eigenbrodt ML and Eigenbrodt EH (1993) Apoptosis and necrosis: basic types and mechanisms of cell death. Arch. Pathol. Lab. Med. 117: 1208-1214

Casciola-Rosen LA, Miller DK, Anhalt GJ and Rosen A (1994) Specific cleavage of the $70-\mathrm{kDa}$ protein component of the $\mathrm{U} 1$ small nuclear ribonucleoprotein is a characteristic biochemical feature of apoptotic cell death. J. Biol. Chem. 269: 30757-30760

Casciola-Rosen LA, Anhalt GJ and Rosen A. (1995) DNA-dependent protein kinase is one of a subset of autoantigens specifically cleaved early during apoptosis. J. Exp. Med. 182: 1625-1634

Casiano CA, Martin SJ, Green DR and Tan EM (1996) Selective cleavage of nuclear autoantigens during CD95 (Fas/APO-1)-mediated T cell apoptosis. J. Exp. Med. 184: $765-770$

Casiano CA and Tan EM (1996) Antinuclear autoantibodies: probes for defining proteolytic events associated with apoptosis. Mol. Biol. Reports 23: 211-216
Columbano A (1995) Cell death: current difficulties in discriminating apoptosis from necrosis in the context of pathological processes in vivo. J. Cell. Biochem. 58: $181-190$

Escargueil-Blanc I, Salvayre R and Negre-Salvayre A (1994) Necrosis and apoptosis induced by oxidized low density lipoproteins occur through two calciumdependent pathways in lymphoblastoid cells. FASEB J. 8: 1075-1080

Farber E (1994) Programmed cell death: necrosis versus apoptosis. Modern Pathology 7: 605-609

Houge G, Robaye B, Eikhom TS, Golstein J, Mellgren G, Gjertsen BT, Lanotte M and Doskeland SO (1995) Fine mapping of 28S rRNA sites specifically cleaved in cells undergoing apoptosis. Mol. Cell. Biol. 15: 2051-2062

Kaufmann SH (1989) Induction of endonucleolytic DNA cleavage in human acute myelogenous leukemia cells by etoposide, camptothecin and other cytotoxic anticancer drugs: a cautionary note. Cancer Res. 49: 5870-5878

Kaufmann SH, Desnoyers S, Ottaviano Y, Davidson NE and Poirier GG (1993) Specific proteolytic cleavage of poly(ADP-ribose) polymerase: an early marker of chemotherapy-induced apoptosis. Cancer Res. 53: 3976-3985

Lennon SV, Martin SJ and Cotter TG (1991) Dose-dependent induction of apoptosis in human tumor cell lines by widely diverging stimuli. Cell Prolif. 24: 203-214

Leist M, Single B, Castoldi AF, Kühnle S and Nicotera P (1997) Intracellular adenosine triphosphate (ATP) concentration: a switch in the decision between apoptosis and necrosis. J. Exp. Med. 185: 1481-1486

Leist M and Nicotera P (1997) The shape of cell death. Biochem. Biophys. Res. Commun. 236: $1-9$

Liu X, Zou H, Slaughter C and Wang X (1997) DFF, a heterodimeric protein that functions downstream of caspase-3 to trigger DNA fragmentation during apoptosis. Cell 89: 175-184

Majno Gand Joris I (1995) Apoptosis, oncosis and necrosis: an overview of cell death Amer. J. Pathol. 146: 3-15

Nicholson D (1996) ICE/CED-3-like proteases as therapeutic targets for the control of inappropriate apoptosis. Nature Biotech. 14: 297-301

Porter AG, Ng P and Jänicke RU (1997) Death substrates come alive. BioEssays 19: $501-507$

Rao L, Perez D and WhiteE (1996) Lamin proteolysis facilitates nuclear events during apoptosis. J. Cell Biol. 135: 1441 - 1455

Rosser BG and Gores GJ (1995) Liver cell necrosis: cellular mechanisms and clinical implications. Gastroenterology 108: 252-275

Sarin A, Wu ML and Henkart PA (1996) Different interleukin-1 $\beta$ converting enzyme (ICE) family protease requirements for the apoptotic death of $\mathrm{T}$ lymphocytes triggered by diverse stimuli. J. Exp. Med. 184: 2445-2450

Shah GM, Shah RG and Poirier GG (1996) Different cleavage pattern for poly (ADPribose) polymerase during necrosis and apoptosis in HL-60 cells. Biochem. Biophys. Res. Comm. 229: 838-844

Shenker BJ, Berthold P, Rooney C, Vitale L, DeBolt K and Shapiro IM (1993) Immunotoxic effects of mercuric compounds on human lymphocytes and monocytes. II. Alterations in B-cell function and viability. Immunopharmacol. Immunotoxicol. 15: 87-112

Shimizu S, Eguchi Y, Kamiike W, Itoh Y, Hasegawa J, Yamabe K, Otsuki Y, Matsuda $\mathrm{H}$ and Tsujimoto $Y$ (1996a) Induction of apoptosis as well as necrosis by hypoxia and predominant prevention of apoptosis by Bcl-2 and Bcl-X $\mathrm{X}_{\mathrm{L}}$. Cancer Res. 56: $2161-2166$

Shimizu S, Eguchi Y, Kamiike W, Waguri S, Uchiyama Y, Matsuda Hand Tsujimoto Y (1996b) Retardation of chemical hypoxia-induced necrotic cell death by BCL-2 and ICE inhibitors: possible involvement of common mediators in apoptotic and necrotic signal transductions. Oncogene 12: 2045-2050

Tan EM (1989) Antinuclear antibodies: diagnostic markers for autoimmune disease and probes for cell biology. Adv. Immunol. 44: 93-151

Thompson CB (1995) Apoptosis in the pathogenesis and treatment of disease. Science 267: 1456-1462

Tidbal JG, Albrecht DE, Lokensgard BE and Spencer MJ (1995) Apoptosis precedes necrosis of dystrophin-deficient muscle. J. Cell Sci. 108: 2197-2204

Watson AJM (1995) Necrosis and apoptosis in the gastrointestinal tract. Gut 37: $165-167$

Wyllie AH, Kerr JFR and Currie AC (1980) Cell death: the significance of apoptosis. Int. Rev. Cytol. 68: 251-305 